\title{
Kansei engineering-based robust design model for logistics services
}

\author{
Markus Hartono ${ }^{1, *}$, Amelia Santoso ${ }^{2}$ \\ ${ }^{1}$ Engineering Management Laboratory, Department of Industrial Engineering, University of \\ Surabaya, 60293 Surabaya, Indonesia \\ ${ }^{2}$ Systems Engineering Laboratory, Department of Industrial Engineering, University of \\ Surabaya, 60293 Surabaya, Indonesia
}

\begin{abstract}
Previous studies in Kansei Engineering have focused on product design and development incorporating customer emotional needs and extended to service design and improvement considering service quality tools to enhance the Kansei Engineering methodology. However, a little attention has been paid to modify the effectiveness of the proposed improvement strategies. This study has developed an integrative model of Kansei Engineering and robust design methodology to strengthen the applicability of Kansei Engineering method in services. An illustrative case study in logistics services has been discussed, as one of the prominent and fastest growing business sectors in Indonesia. The expected contributions in theory and practice are expressed in this paper.
\end{abstract}

\section{Introduction}

Products and services are deemed useful and beneficial when they fit to customer need and requirement. However, an error called as noise is potentially existed during the manufacturing or development process. As consequence, there will be a chance to produce flaws, defects, and failures in products or services. Surely, noise should be reduced and removed. Eventually, loss of profit and customer loyalty will be potential risks.

There are several ways to manage the noise [1], namely, (i) $100 \%$ screening, (ii) change technology, and (iii) robust design. The $100 \%$ screening and change technology are deemed expensive. Thus, robust design is promoted, due to its cost-free character. A product or process is called robust when it is insensitive to any noise or unintended conditions. Insensitivity of performance due to both changes in environment and variations in the characteristics of design components should be addressed [2].

Apart from physical products, the demand for services is highly competitive. Services are considered important since they full of human characteristics and needs, such as responsiveness, reliability, insurance and satisfaction [3]. Since the growth of service industry is rapidly increasing, hence, the study on this area is of urgently required. The

\footnotetext{
* Corresponding author: markus@staff.ubaya.ac.id
} 
challenge is that many services offered are of the equivalent function and quality in the market. Hence, it brings difficulties for the customers to choose the best one and distinguish among the alternates [4]. More specifically, the customers show their preferences shifting from functional into meaning and emotional. According to Khalid and Helander [5], it is full of emotions rather than rational process or cognition which drives the final decision. In Japanese, this process is called as Kansei. A popular method which incorporates Kansei into product and service design and development is known as Kansei Engineering [6]. Kansei Engineering (KE) is a powerful ergonomics-based methodology for product design and development which is translating emotional needs into product characteristics. Hartono and Tan [7] extended the application of KE into services as the fastest growing sector in today's economy. Some case studies on services have been conducted, including hotel, banking, shopping center, and logistics. The latest one, which is logistics services, is of high interest since it is one of the fastest growing service sectors in Indonesia and rest of the world. Thus, the opportunity of exploring the characteristics of logistics service and its initiatives for continuous improvement is widely open. This motivates our current study.

Recent KE studies on services have put high efforts on the integration of KE methodology and service quality tools (such as SERVQUAL, Kano model, Quality Function Deployment (QFD), and TRIZ) to increase the service excellence [see 7, 8, 9, 10]. The most recent one is that a study of integrating KE, Kano and QFD in the logistics services to generate more innovative ideas for improvements [10]. However, the robustness of proposed improvements will be questioned. Perhaps they are valid for now; whether they are robust is questionable. Moreover, the ideas for improvement are mostly derived from the designer's point of view, not much involving the relevant stakeholders. It may potentially produce more biases. A research on the robustness of service improvement is still rare. The robustness using Taguchi method in the Kansei Engineering applied in services has been explored by Hartono [11]; more recently the service improvements have been extended through a relatively more structured methodology incorporating Taguchi principle [12]. Hence, a study of how KE is engaged with robust-based methodology for logistics service design is of highly interesting and will be discussed in this paper.

This objective of this study is to propose an integrative model of Kansei Engineeringbased robust design for logistics services and discuss its potential applicability by providing an illustrative numerical example. Some prominent service quality tools are included, e.g., SERVQUAL, Kano model and House of Quality (HOQ).

\section{Kansei Engineering in Services}

Kansei Engineering (KE) is a powerful product and service design methodology which grabs and captures the emotional needs and feelings of potential users and customers, then translates them into product and service design characteristics and elements. The most prominent superiorities of this method are that its ability to figure out the unspoken needs of customer and quantify them into customer needs [7]. In addition, this method can be integrated with other service tools to strengthen its applicability and to promote flexibility due to the dynamics of customer demands [10].

\subsection{Kansei, Emotional Needs and Kansei Engineering}

As previously discussed, Kansei Engineering (KE) starts with what emotions required by the customers and how to satisfy them. In Japanese, the concept of emotional needs and satisfaction is known as Kansei. There are ubiquitous definitions of emotions in the literatures. They appear in the studies of product design, service design and management, marketing, psychology and human factors. Back to Kansei as the synonym 
of emotion, it is defined as customer psychological feelings and images of a new product which later builds significant impressions [6]. Kansei is said to be difficult to translate, it is more than emotions and feelings, rather it is related to the entire feelings of human being when he or she gets something more than expected. The illustration of how Kansei is defined is provided in the Figure 1 below.

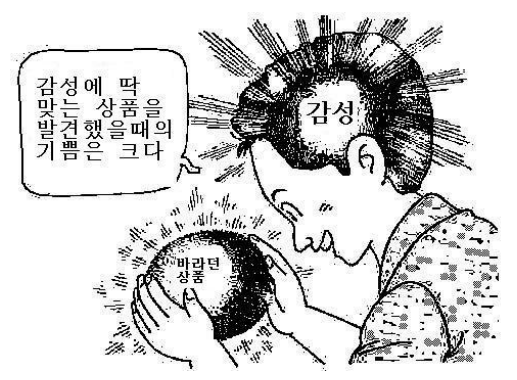

Fig. 1. The definition of Kansei [adopted from [13]]

The product or service will sell once they meet the customer emotional needs [6]. Thus, service and product designer should strive to deliver product and service which satisfy customer feelings and emotions. In a similar case, Kano's model tries to distinguish service performance into three main categories, namely basic/must-be, one-dimensional and attractive/delighter. The one categorized as attractive/delighter forms a significant Kansei $[6,10]$. Otherwise, our customers will leave and move to competitors. This situation is strengthened by the fact that customer demand is always changing.

Since 1970s, the KE methodology has been built and proposed to capture customer emotional needs and translate them into product characteristics, initially done for Mazda Miata sport car. One of the superiorities of KE methodology is that to build the quantitative relationship between perceived emotional response and design characteristics. It seems that Kansei is a function of perceived service attributes, in other form it is written as follows: Kansei $=\mathrm{f}$ (perceived service attributes) [6]. The interactive mapping between Kansei and design properties intermediated by affective channel is shown in Figure 2.

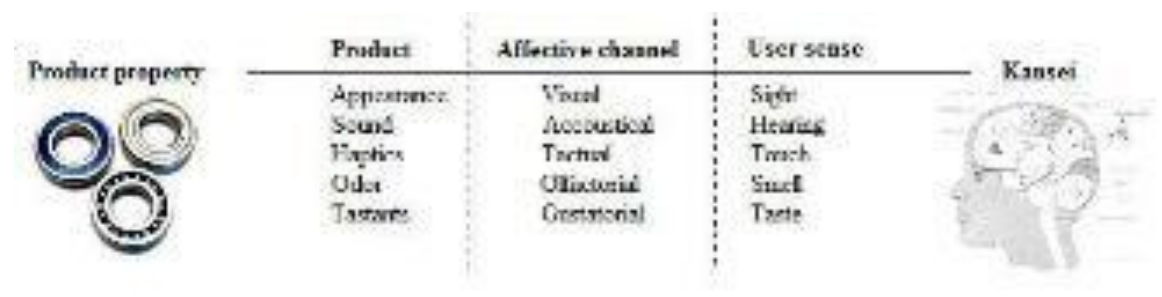

Fig. 2. The affect/Kansei flow [14]

\subsection{Quality and Robust Design in Kansei Engineering}

Quality for product and service design is something which fulfils what is required by the users and customers. In terms of affect and emotional design, quality is defined as 
something that can achieve the happiness for people in the areas of production, use and reuse. More specifically, services are called being qualified once they can create an interactive harmony between users and designers [15].

Back to the methodology of KE, there are two important components of service design and development, i.e., (i) Kansei/affective aspects/emotional impacts and (ii) service attributes/properties. It is referred to the general terms of product and service interactions [14], which are design parameters and product/service traits. The design parameters are the ones called as the main properties of services, which may be referred to service attributes and may have impacts on Kansei. In contrast, product/service traits are the ones not intended by the designer and customer, but they are blended in the package of services offered.

Hence, the role of robust emotional design for services is of interesting. The service traits are called as the uncontrollable factors or noise, whereas the service attribute design parameters are regarded as the controllable factors. The robust emotional design or called as Kansei Engineering-based robust design for services will assist the service designer in enhancing the emotional/feeling quality of their service attributes. More specifically, the feeling quality here is to obtain the customer requirement and expectation. This robust design promotes simple experimental phases to determine the optimal design parameter settings by analysing the complex relationships between the controllable factors (design parameters), the uncontrollable factors (noise factors), and the quality performance [11].

\section{Proposed Model and Discussion}

This study proposes an integrative model of Kansei Engineering, Kano and SERVQUAL incorporating robust design methodology for service design and improvement. The highlights of this proposed model are on the minimization of noise (as shown in the Figure 3 ) and the quality of feelings/emotions/Kansei of services offered. A case study as the purpose of illustrative numerical example is taken from logistics services.

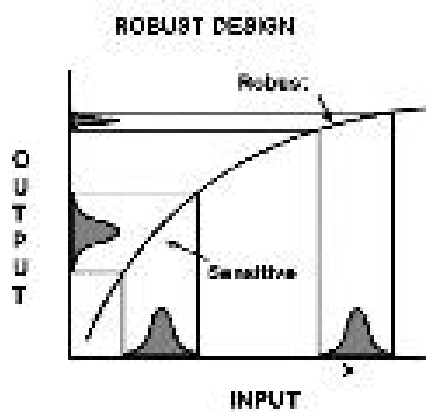

Fig. 3. Robust design for services and products $[1,2]$

With regard to robust design and Kansei Engineering methodology, a full integrated model Kansei-based robust design for logistics services is proposed, as shown in Figure 4. It starts with choice of service domain (i.e., logistics services), followed by the spanning 
two main attributes, namely, Kansei and SERVQUAL. Kano model is inserted to filter only logistics service attribute with Kano's attractive category (known as delighter) and onedimensional one as the main driver for Kansei. Through the measurement of cognitive customer satisfaction (i.e., satisfaction $=($ perception - expectation $) *$ importance level $)$, the negative satisfaction will be the focus for improvement, and checked its impact on Kansei. The significant logistics service attributes will be continued for matching with improvement strategies/initiatives. The complete methodology is provided in a study by Hartono et al. [10]. A new contribution is made by incorporating robust design methodology through Taguchi method. The controllable and uncontrollable factors are defined, and the objective is that to minimize noise and to achieve optimal proposed strategies.

Trough a case study of logistics services, taken from Hartono et al. [10], there are several critical service attributes, shown in Table 1. It is assumed that the attribute "cleanliness of helmet for customers" and "web-based application interface" are the most critical. A two-level HOWs strategies will be generated, such as, (i) modular system for helmet, and (ii) integrated system for helmet for the first attribute, whereas,

(i) interactive apps, and (ii) non-interactive apps for the second attribute. Through $\mathrm{S} / \mathrm{N}$ ratio using response as large as possible (the larger the better), i.e., $\mathrm{SN}_{\mathrm{L}}=-10 \log _{10}(1 / \mathrm{n}$ $\left.\sum\left(1 / \mathrm{y}_{\mathrm{i}}\right)_{2}\right)$ and $\mathrm{L}_{4}\left(2^{3}\right)$ design, the optimal level combination of each service attribute will be performed.

Table 1. Importance weight of critical logistics service attributes

\begin{tabular}{|c|c|c|c|c|c|c|c|c|}
\hline No & Code & $\begin{array}{c}\text { Logistics service } \\
\text { attributes }\end{array}$ & $\begin{array}{l}\text { Satisfaction } \\
\text { score }\left.\right|^{*}\end{array}$ & \multicolumn{2}{|c|}{$\begin{array}{c}\text { Kano } \\
\text { weight }\end{array}$} & \multicolumn{2}{|c|}{ Kansei score } & $\begin{array}{c}\text { Importance } \\
\text { weight } * *\end{array}$ \\
\hline 1 & T2 & Cleanliness of vehicle & 3.47 & A & 4 & Secured & 3.91 & 54.27 \\
\hline \multirow{3}{*}{2} & \multirow{3}{*}{ T6 } & \multirow{3}{*}{$\begin{array}{l}\text { Web-based application } \\
\text { interface }\end{array}$} & \multirow{3}{*}{1.58} & \multirow{3}{*}{ A } & \multirow{3}{*}{4} & Friendly & 3.79 & \multirow{3}{*}{74.00} \\
\hline & & & & & & Innovative & 3.83 & \\
\hline & & & & & & Helped & 4.09 & \\
\hline \multirow{4}{*}{3} & \multirow{4}{*}{$\mathrm{T} 7$} & \multirow{4}{*}{$\begin{array}{l}\text { Cleanliness of helmet } \\
\text { for customer }\end{array}$} & \multirow{4}{*}{5.73} & \multirow{4}{*}{$\mathrm{O}$} & \multirow{4}{*}{2} & Professional & 3.57 & \multirow{4}{*}{165.25} \\
\hline & & & & & & Innovative & 3.83 & \\
\hline & & & & & & Cheap & 3.32 & \\
\hline & & & & & & Precise & 3.70 & \\
\hline
\end{tabular}




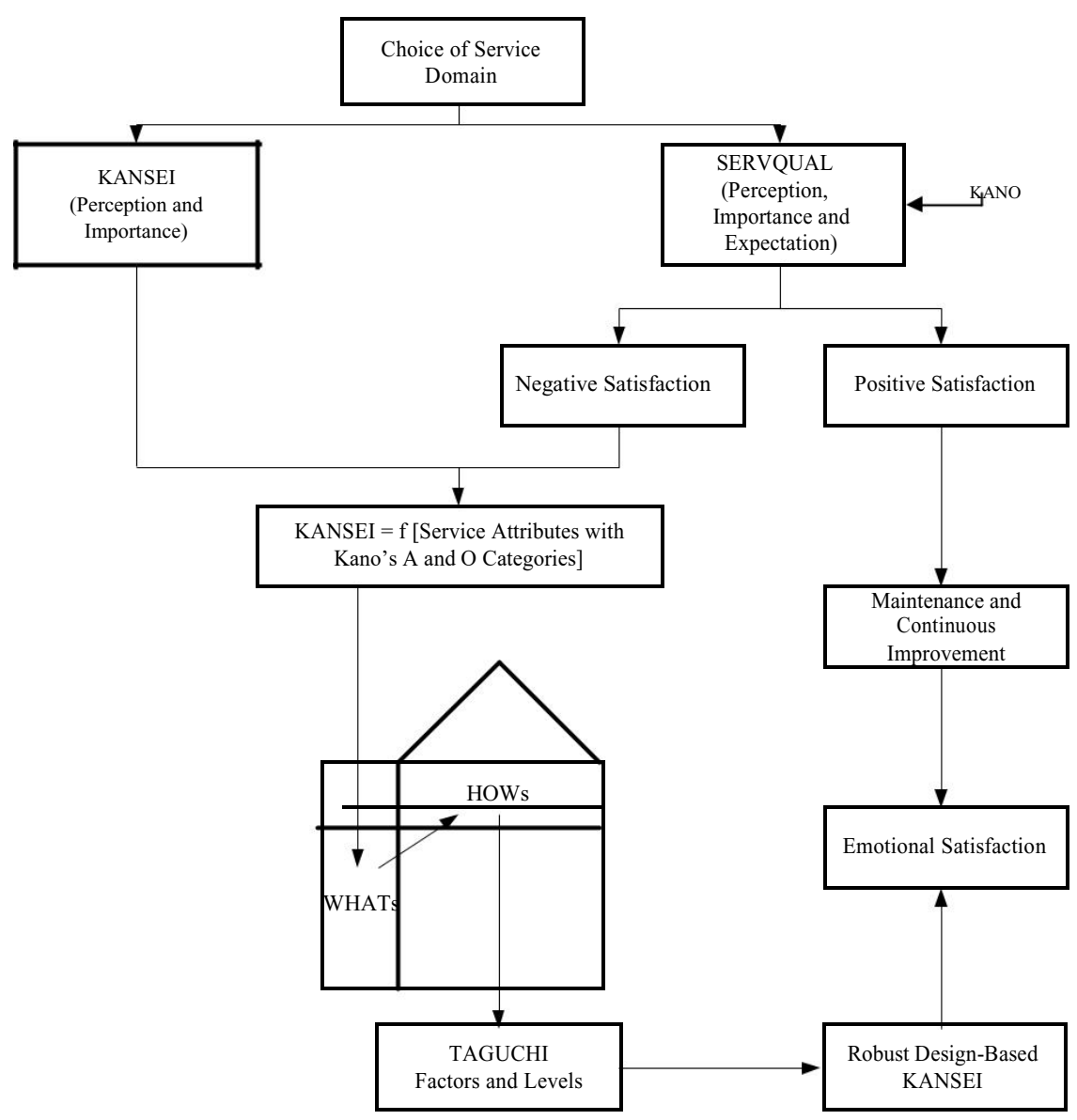

Fig. 4. Model of Kansei-based Robust Design for Logistics Services.

\section{Conclusions and Further Research Recommendation}

This study proposes a conceptual model of Kansei Engineering bringing along the robust design methodology for logistics services. The contribution, of both theoretically and practically, is that how to minimize noise and promote effectiveness of the proposed improvements for logistics services. For future research, a real case study on logistics services should be taken, to test the applicability of the proposed conceptual model.

\section{References}

1. T. N. Goh, Quality Engineering Applications of Statistical Design of Experiments (John Wiley \& Sons, Asia Pte Ltd, 2005)

2. G. E. P. Box, G. S. Hunter, W. G. Hunter, Statistics for Experimenters: Design, Innovation, and Discovery (John Wiley \& Sons, Inc, New Jersey, 2005)

3. A. Parasuraman, L. L. Berry, V. A. Zeithaml, Journal of Retailing 64, 12 - 40 (1988) 
4. H. N. J. Schifferstein, P. Hekkert, Product Experience (Elsevier Ltd, Oxford, UK, 2008)

5. H. M. Khalid, M. G. Helander, Concurrent Engineering: Research and Applications 14, $197-206$ (2006)

6. M. Nagamachi, International Journal of Industrial Ergonomics 15, 3 - 11 (1995)

7. M. Hartono, K. C. Tan, Ergonomics 54, 987 - 1004 (2006)

8. M. Hartono, H. Raharjo, Total Quality Management \& Business Excellence 26, 971 985 (2015)

9. M. Hartono, International Journal of Technology 7, 97 - 104 (2016)

10. M. Hartono, A. Santoso, D. N. Prayogo, International Journal of Technology, 8, $1070-$ 1081 (2017)

11. M. Hartono, Proceedings of $5^{\text {th }}$ National Industrial Engineering Conference, $347-358$ (2009)

12. M. A. Hadiyat, IOP Conference Series: Material Science and Engineering 316, 1 (2018)

13. M. Nagamachi, A. M. Lokman, Innovation of Kansei Engineering (CRC Press, Taylor \& Francis Group, (2011)

14. S. Schütte, Thesis. Linkoping University, Linkoping, (2005)

15. M. Hartono, H. Raharjo, Total Quality Management \& Business Excellence 26, 971 985 (2015) 